incorporadas novas texturas e sabores na dieta infantil. Os primeiros alimentos a ser introduzidos são os legumes e a fruta. A ingestão excessiva de hidratos de carbono nesta fase pode desencadear problemas de saúde tais como a obesidade, diabetes, cárie dentária, o que demonstra a importância de analisar os boiões/saquetas de fruta dados a crianças como opção de lanche, em substituição de uma peça de fruta. O objetivo deste estudo consiste em avaliar as tabelas nutricionais de boiões/saquetas de fruta industriais comercializados para crianças/bebés e disponíveis nas grandes superfícies em Portugal. Materiais e métodos: Toda a informação foi recolhida fisicamente e online em cinco superfícies comerciais portuguesas (Continente ${ }^{\circledR}$, Pingo Doce ${ }^{\circledR}$, Lidl $^{\circledR}$, Jumbo ${ }^{\circledR}$ e Celeiro ${ }^{\circledR}$ ). Foi criada uma base de dados em Excel ${ }^{\circledR}$ com as tabelas nutricionais dos 139 boiões diferentes de frutas encontrados, que pertenciam a 12 marcas distintas. Resultados: A quantidade de açúcar nos boiões avaliados foi extremamente díspar (entre 7,8 e 20,2g para uma embalagem de $100 \mathrm{~g}$ ), sendo que nenhum dos 139 produtos analisados foi classificado como tendo baixo teor de açúcar $(\leq 5 \mathrm{~g} / 100 \mathrm{~g})$. A ingestão de açúcar diária de uma criança de 1-2 anos não deve ultrapassar as 90kcal/dia, sendo que o boião que apresentou menor conteúdo calórico contém 43kcal. Os boiões de fruta com biscoito/bolacha ou banana são os que têm valores mais altos de açúcar e o conteúdo em sal é elevado quando os boiões contêm biscoito/bolachas ou cereais. Conclusões: Apesar de serem apresentados aos pais como saudáveis, estes boiões de fruta industrializados deveriam ser dados apenas de forma esporádica e não como substituição da porção de fruta diária pelo alto teor de açúcar que contêm. É importante realçar a necessidade imperiosa de ler e interpretar as tabelas nutricionais presentes nos rótulos destes boiões.

http://doi.org/10.24873/j.rpemd.2019.12.629

\section{\#172 Atratividade da Face e Cefalometria Clínica - Estudo de Regressão Quadrática}

Joana Godinho*, Diana Fernandes, Patrícia Pires, Luis Jardim

FMDUL

Objetivos: O presente estudo teve por objetivo avaliar a possível existência de uma correlação quadrática entre várias medições cefalométricas e a atratividade da face, avaliada em fotografias de frente em repouso, de frente a sorrir e de perfil. Materiais e métodos: Vinte e uma medições cefalométricas foram obtidas a partir de teleradiografias de perfil de 60 indivíduos com padrões sagitais de classe I, II e III, 20 com cada tipo de relação esquelética. As radiografias foram obtidas antes do tratamento ortodôntico e as classes II e III tinham indicação para tratamento cirúrgico-ortognático. A atratividade da face foi avaliada em fotografias vistas de frente, de frente a sorrir e de perfil, por um grupo de leigos através de uma Escala Visual Analógica. A eventual presença de uma correlação não-linear, de forma parábolica, entre a atratividade e os valores obtidos na análise cefalométrica das radiografias de perfil foi avaliada com uma análise de regressão quadrática. O nível de significancia estatistica foi fixado em $5 \%$. Resultados: A atravidade da face de frente em repouso, correlacionou-se de forma sig- nificativa com a distância do lábio superior ( $p=0.002 ; \mathrm{r}=0.45$ ) e inferior ( $p=0.005 ; r=0.41)$ à linha $\mathrm{Sn}-\mathrm{Pg}$; com a distância do lábio inferior à linha Prn-Pg' ( $p=0.009 ; r=0.39$ ); e com os ângulos do plano mandibular ( $p<0.000 ; r=0.51$ ) e ANB ( $p=0.004$; $r=0.42$ ). A face de frente a sorrir correlacionou-se com a distância do lábio superior ( $p=0.001 ; \mathrm{r}=0.46)$ e inferior $(p=0.004$; $\mathrm{r}=0.42$ ) à linha Sn-Pg'; e os ângulos do plano mandibular ( $\mathrm{p}=$ $0.001 ; r=0.48)$ e SNB ( $p<0.003 ; r=0.44)$. A atratividade do perfil correlacionou-se com a distância do lábio superior $(\mathrm{p}=$ $0.004 ; r=0.42$ ) e inferior ( $p=0.006 ; r=0.41$ ) à linha Sn-Pg'; com a distância do lábio inferior à linha Prn-Pg' ( $p=0.006 ; r=0.41)$; e com o ângulo do plano mandibular ( $p<0.001$; $r=0.46)$. Conclusões: Foram encontradas correlações entre diversas variáveis cefalométricas que medem a protrusão labial e a atratividade da face, não só no perfil mas também nas vistas de frente em repouso e a sorrir. Algumas medições dos tecidos duros, especialmente o ângulo do plano mandibular, também revelaram uma correlação significativa com a atratividade da face. Estas correlações têm a forma de uma parábola, existindo um valor cefalométrico ideal que corresponde ao máximo de atratividade, a partir do qual esta decresce. Estes valores não coincidem com as normas cefalométricas.

http://doi.org/10.24873/j.rpemd.2019.12.630

\#173 Força de adesão de brackets ortodônticos a dentes decíduos utilizando diferentes adesivos CrossMark

Sara Reis*, Pedro Mariano Pereira, Luís Proença

Instituto Universitário Egas Moniz

Objetivos: A dentição decídua apresenta características histopatológicas e morfológicas específicas que devem ser consideradas nos protocolos de adesão. Até à data, poucos foram os estudos realizados sobre a adesão de brackets ortodônticos a dentes decíduos, em contraste com um elevado número de investigações detalhadas em dentes permanentes. $\mathrm{O}$ objetivo principal da investigação é comparar a força de adesão de brackets ortodônticos, utilizando os adesivos Assure ${ }^{\circledR}$ Plus All (Reliance Orthodontic Products) e Transbond ${ }^{\text {TMXT Light }}$ Cure (3M, Unitek), em dentes decíduos e permanentes. Materiais e métodos: Foram selecionados 22 molares decíduos e 22 pré-molares hígidos e divididos em quatro grupos de 11 dentes. No Grupo 1 (pré-molares) e no Grupo 3 (molares decíduos), foi utilizado o adesivo Assure ${ }^{\circledR}$ Plus All na colagem de brackets metálicos. $\mathrm{O}$ adesivo Transbond ${ }^{\mathrm{TM} X T}$ foi usado no Grupo 2 (pré-molares) e no Grupo 4 (molares decíduos). Em todos os grupos utilizou-se a pasta adesiva Transbond ${ }^{\mathrm{TM}}$ XT. A amostra foi sujeita à termociclagem a 10.000 ciclos em água, em banhos alternados de $5 .{ }^{\circ} \mathrm{C}$ e $55 .{ }^{\circ} \mathrm{C}$. A força de adesão foi determinada por teste de cisalhamento, à velocidade de $1 \mathrm{~mm} / \mathrm{min}$, e o local de falha de adesão foi determinado através do Índice de Remanescente Adesivo (ARI). Para o tratamento estatístico dos dados foi utilizada a ANOVA Two-way e o teste Kruskal-Wallis, sendo fixado um nível de significância de $5 \%$ ( $p \leq 0,05)$. Resultados: Não se verificaram diferenças estatisticamente significativas na força de adesão entre sistemas de adesão, nem entre dentes decíduos e dentes permanentes. No entanto, há uma tendência para uma força de adesão mais elevada nos 
dentes decíduos colados com o Assure ${ }^{\circledR}$ Plus All do que com o TransbondTMXT. A falha de adesão de todos os grupos ocorreu predominantemente na interface adesivo-bracket (ARI 1), à exceção do grupo onde foi utilizado o Transbond ${ }^{\mathrm{TM}}$ XT em dentes permanentes, onde a falha de adesão ocorreu predominantemente na interface esmalte-adesivo (ARI 2). Conclusões: Ambos os adesivos são adequados para a adesão de brackets ortodônticos a dentes decíduos e a dentes permanentes, tendo-se obtido médias de força de adesão iguais ou superiores aos recomendados como clinicamente eficazes, garantindo uma boa eficiência clínica.

http://doi.org/10.24873/j.rpemd.2019.12.631

\#174 Avaliação da maturação da sutura palatina mediana em radiografias panorâmicas

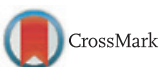

Ana Catarina Vaz*, Francisco Espinha, Mariana Almeida, Sofia Isabel Madeira Reis, Eugénio Martins, Maria João Ponces

\section{FMDUP}

Objetivos: O objetivo deste estudo foi validar a utilização do Sistema de Classificação BOKA (um método recentemente divulgado em congressos internacionais de Ortodontia) na avaliação da maturação da sutura palatina mediana em ortopantomografias, ao compará-lo com o método analítico da maturação das vértebras cervicais proposto por Baccetti (Baccetti et al., 2005), que está descrito na literatura como adequado na determinação da idade esquelética de indivíduos sujeitos a expansão maxilar e, portanto, no processo decisório da modalidade terapêutica a empreender. Materiais e métodos: Dois investigadores foram treinados para usar o método de Baccetti e o Sistema de Classificação BOKA. Analisaram independentemente um total de 77 telerradiografias em incidência de perfil e 77 ortopantomografias aleatoriamente selecionadas a partir dos processos clínicos do Departamento de Ortodontia da Faculdade de Medicina Dentária da Universidade do Porto, em 2 ocasiões distintas. Os erros interexaminador e intraexaminador foram calculados recorrendo ao Coeficiente Kappa de Cohen ponderado. A correlação entre as duas escalas foi determinada utilizando o Coeficiente de Correlação de Spearman, bem como o Coeficiente de Correlação Intraclasse. Foi considerado um nível de significância de $5 \%$. Resultados: 0 método BOKA Grading System demonstrou uma correlação boa/ muito boa tanto para o erro interobservador $(k=0,874)$ como para o erro intraobservador $(\mathrm{k}=0,869$ para o observador 1 e $\mathrm{k}=0,794$ para o observador 2). As percentagens de concordância foram superiores para o observador 1, relativamente ao observador 2 . Para o método de Baccetti, o valor de Kappa foi superior a 0,80 para os erros interobservador e intraobservador, sendo as percentagens de concordância superiores a 75\%. A correlação entre os métodos BOKA e de Baccetti mostrou-se baixa/moderada, com um Coeficiente de Correlação Intraclasse de 0,666 e um Coeficiente de Correlação de Spearman de 0,484. Conclusões: O Sistema de Classificação BOKA e o método de Baccetti têm uma reprodutibilidade boa a muito boa. O Sistema de Classificação BOKA não é suficientemente válido para ser utilizado de forma isolada na avaliação da maturação da sutura palatina mediana e na decisão da modalidade terapêutica a empreender em caso de deficiência transversal maxilar.

http://doi.org/10.24873/j.rpemd.2019.12.632

\section{\#175 Medicina Dentária do Sono: uma realidade na prática clínica do Médico Dentista?}

Jorge Miguel de Oliveira Martins*, Carlos Ferreira de Almeida, Ana Rita Carvalho, Filomena Capucho, Susana Silva

Universidade Católica Portuguesa, Centro de Estudos de Comunicação e Cultura (CECC), Faculdade de Ci, Universidade Católica Portuguesa, Centro Interdisciplinar de Investigação em Saúde (CIIS)

Objetivos: Perceção internacional do impacto da Medicina Dentária do Sono através do estudo dos conhecimentos dos Médicos Dentistas relativos ao diagnóstico e tratamento da roncopatia e da Síndrome da Apneia Obstrutiva do Sono, da sua experiência clínica, bem como das opiniões destes profissionais sobre o tratamento multidisciplinar destas patologias. Materiais e métodos: Para este estudo correlacional por amostragem do tipo observacional, descritivo e transversal foi realizado um questionário semiaberto que, para além de elaborado em português foi traduzido para castelhano e inglês. A linguagem dos questionários foi previamente avaliada por uma especialista em linguística nos idiomas supracitados. Adicionalmente, dois Médicos Dentistas nativos em cada um dos referidos idiomas reviram os questionários e avaliaram as traduções. Estes incluíam questões relativas a: caracterização da amostra, prática clínica, conhecimentos teóricos e opiniões. Os questionários foram distribuídos aos referidos profissionais em papel e divulgados/difundidos através da plataforma online Google Forms ${ }^{\circledR}$. Os dados foram analisados estatisticamente com recurso ao IBM ${ }^{\circledR}$ SPSS $^{\circledR}$, tendo sido utilizado um nível de significância de 5\%. Resultados: Obtiveram-se 236 respostas válidas nos cinco continentes. 35,2\% referiram ter formação/ certificação, após a graduação, relativa a estas patologias. A minoria (20,8\%) afirmou integrar uma equipa multidisciplinar do sono. Quando necessitam de realizar terapêutica para estas patologias, a abordagem mais utilizada são os dispositivos intraorais removíveis de avanço mandibular. Na maioria das questões que aferiram os conhecimentos teóricos, estes profissionais responderam corretamente. A minoria $(28,0 \%)$ dos Médicos Dentistas concorda ou concorda totalmente que a formação académica que possui é suficiente para realizar tratamento para estas patologias. Por outro lado, 54,2\% dos elementos da amostra concordam ou concordam totalmente que os Médicos Dentistas podem detetar, diagnosticar e/ou tratar as referidas patologias. A maioria (69,5\%) destes profissionais reconhece que o tratamento multidisciplinar num espaço clínico único é o mais adequado. Conclusões: Apesar do significativo desenvolvimento da Medicina Dentária do Sono ao longo das últimas décadas, existe uma clara necessidade de maior formação dos Médicos Dentistas de forma colmatar as lacunas e erradas conceções identificadas. Existe, também, a necessidade de maior integração destes profissionais nas equipas multidisciplinares do sono.

http://doi.org/10.24873/j.rpemd.2019.12.633 